\title{
Development of Enpp1 Inhibitors as a Strategy to Activate Stimulator of Interferon Genes (STING) in Cancers and Other Diseases
}

\author{
Manas Sharma ${ }^{1}$, Trason Thode ${ }^{2}$, Alexis Weston ${ }^{2}$ and Mohan R Kaadige ${ }^{2 *}$ \\ ${ }^{1}$ Brophy College Preparatory, USA \\ ${ }^{2}$ Applied Cancer Research and Drug Discovery, Translational Genomics Research Institute, USA
}

Submission: August 25, 2018; Published: September 10, 2018

*Corresponding author: Mohan R Kaadige, Translational Genomics Research Institute 445 N Fifth Street, Phoenix, AZ 85004, USA;

Tel: 602-343-8453; Fax: 602-916-0602; Email: mkaadige@tgen.org

\begin{abstract}
Ecto-nucleotide pyrophosphatase/phosphodiesterase-1 (ENPP1/NPP1) is a membrane-bound nucleotide metabolizing enzyme that is implicated in a variety of physiological and pathological conditions. Recently, ENPP1 was discovered as the dominant 2'3'-cGAMP hydrolyzing enzyme. 2'3'-cGAMP is the endogenous STING agonist, generated from breakdown of cytosolic DNA by cGAS. Hydrolysis resistant 2'3'-cGAMP's have been demonstrated to be potent activators of STING-dependent innate immunity and these are currently undergoing clinical trials in cancer Here we discuss ENPP1 as a potential therapeutic target for activation of STING-dependent innate immune response.
\end{abstract}

Keywords: Innate immunity; STING; ENPP1/NPP1; Cytokines; Immunotherapies; Interferon; T-cell priming

\section{Introduction}

Innate immunity is the first response in the human body against pathogenic, or disease-causing stimuli. These stimuli can vary, and include viruses, perturbed normal tissue, and dying cancer cells. It is an important response, as it prevents continued proliferation of these pathogens and maintains a state of homeostasis within the body. It can also accommodate the development of a specific induced immune response during the first, or primary infection and, can therefore, establish inflammatory conditions. This induced response is specific because of the many different expressions that the cell surface gives off in the form of pattern recognition receptors, which can identify many of the molecules of life, such as, polysaccharides, glycoproteins, glycolipids, and nucleic acids [1].

The definition of innate immunity has altered over time. In earlier years, it was believed that innate immune response was premeditated. However, recent studies have shown that innate immunity is actually a specific response that results from damage or pathogen-associated molecular patterns (DAMP/ PAMPs) [2]. In the initial phase, the innate immune system is able to coordinate inflammatory responses through cells of the hematopoietic compartment (neutrophils, macrophages and monocytes) and create conditions suitable for microbial clearance. In the second phase, other cells like dendritic cells are able to process antigens and present them on the surface in concert with major histocompatibility complex (MHC) to prime T-cells. This also allows the body to more effectively fight against infections of the same or similar type in the future. This "memory" is dependent on two specific types of cells: natural killer (NK) cells and macrophages. These cells provide crucial protection against reinfection in the immune system [3]. This "memory" found in innate immune systems is present in both vertebrate and invertebrate organisms.

\section{Cytokines in Innate Immune Response}

Cytokines are possibly the most indispensable component of the innate immune response. Cytokines are secreted by cells of the immune system and facilitate interaction between different types of cells. There are many different types of cytokines, and they are classified mainly by their biological functions. The main types of cytokines are: interferons (INFs), interleukins (ILs), transforming growth factors (TGFs), and tumor necrosis factors (TNFs) [4]. Interferons are the most commonly found type of cytokine in vertebrates and mammals and are crucial to mediate antiviral defense. To date, there have been three types of interferons discovered in vertebrates, and specifically mammals: Types 1, 2 and 3. Type 1 IFNs typically facilitate the antiviral response against microbial infection-causing pathogens. Type 
2 IFNs also facilitate antiviral response, but at the same time, vitalize the process of phagocytosis and inhibit cell growth. Type 3 IFNs have been demonstrated to be strikingly similar in function to Type 1 IFNs [5,6]. Interleukins are a type of cytokines that also facilitate inflammatory responses in the immune system and help to stimulate cell growth [7]. Transforming growth factors (TGFs) regulate cell growth, help stimulate the growth of oocyte cells (which are found in the ovum), repair wounds inflicted upon the body, participate in immunosuppression, or reduce the activity of the immune system when naturally required [8]. Finally, tumor necrosis factors (TNFs) help to stimulate macrophages as they participate in the biological process of phagocytosis [9].

\section{STING (Stimulator of interferon genes) as a DNA sensor}

STING has been identified as a major signaling molecule that plays a pivotal role in innate immune response by inducing the production of interferons. STING is a cytoplasmic pattern recognition receptor activated by nucleic acid ligands known as cyclic dinucleotides (CDNs). These CDNs are generated by the DNA sensor cyclic GMP-AMP synthase (cGAS) using cytosolic DNA from extrinsic pathogens or endogenous aberrant self-DNA [10-12]. In case of tumors, it is probable that dying tumor cells are sources of dsDNA in the cytoplasm. In addition to CDN's, STING can directly sense DNA and this dual sensing has been uncoupled with specific mutations in STING [10]. Activation of STING induces its binding with a kinase TBK1 (TANK-binding kinase 1) and further phosphorylation and dimerization of IRF3 (Interferon regulatory factor 3). IRF3 and another transcription factor that is activated by STING (STAT6) translocate to nucleus and bind to interferon promoters leading to production of type I interferons.

It is suggested that STING pathway is the main innate immune sensing pathway within tumor microenvironment and the main cell types in the tumor microenvironment that produce type I interferons are the dendritic cells [13,14]. In addition to the activation of STING pathway in response to tumor-derived DNA, dendritic cells prime T-cells by presenting tumor- associated antigens. These effects then create a signaling pathway, which allows T-cells, a main feature of the active immune response, to neutralize tumor cells $[15,16]$. Some tumor cells are able to "disguise" themselves to the innate immune response by upregulating immune checkpoints, or by having a lack of innate immune response within the tumor. A recent study reported that STING is epigenetically silenced in some cancers [17]. Additionally, oncoproteins from viruses such as human papillomavirus can bind and block activation of STING [18]. Thus, a cytosolic DNA sensing pathway is important for activation of innate immune response. In recent years, there has been considerable interest in the field of immune-oncology as well as an increase in the number of immunotherapies available $[19,20]$.

\section{ENPP1(Ectonucleotide Pyrophosphatase/Phosphodi-} esterase-1) And Its Role in Innate Immunity

ENPP1 is a membrane bound enzyme that is an important regulator of extracellular inorganic pyrophosphate in osteoblasts and chondrocytes [21]. It is essential for prevention of soft tissue mineralization and ENPP1 deficient mice can have abnormal gait and progressive calcification in ectopic sites [22]. ENPP1 is responsible for hydrolysis of extracellular nucleotide triphosphates to produce inorganic pyrophosphates (PPi) [23]. Recent investigations have shown that ENPP1 plays a much larger role in limiting the innate immune response of the human body. It has been discovered that STING pathway is regulated by ENPP1[24]. ENPP1 was identified as the major hydrolase for the most potent endogenous CDN ligand for STING: 2'3'-cGAMP [25]. Importantly, it was demonstrated that denaturation of 2'3'-cGAMP can control the activation of the STING pathway [26]. Phosphothioate analogs of 2'3'-cGAMP resistant to ENPP1- mediated hydrolysis potently activate STING [25] and mediate anti-tumor responses. These analogs have now entered clinical trials as intra-tumoral injections in various advance cancers (Figure 1).

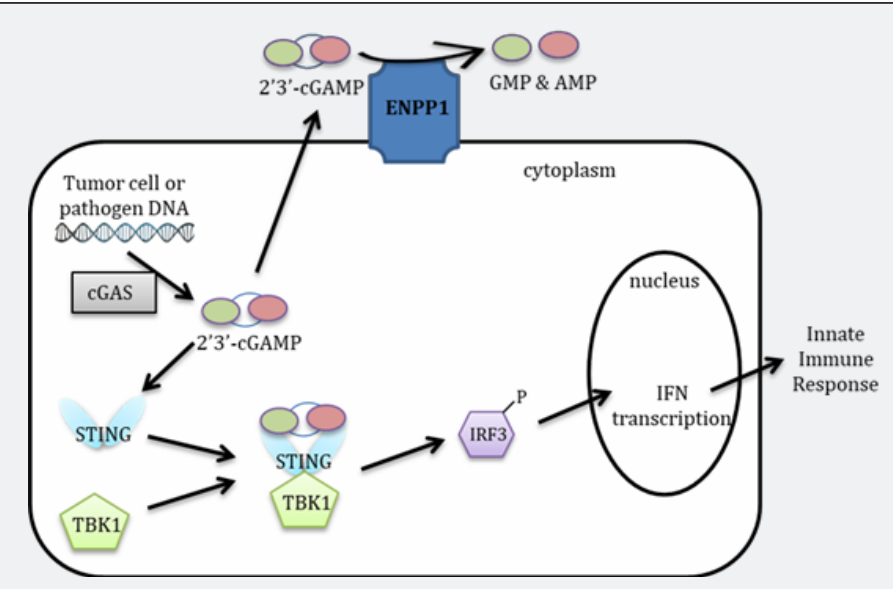

Figure 1: Role of ENPP1 in the STING pathway. Tumor cell DNA released from dead cells and pathogen DNA is processed by cGAS (cyclic GMP-AMP synthase) to generate 2'3'-cGAMP dinucleotide. Binding of 2'3'-cGAMP to STING leads to activation of STING and subsequent recruitment of TBK1 (TANK-binding kinase 1). This leads to phosphorylation and nuclear translocation of IRF3, where IRF3 drives transcription of type I interferons. ENPP1 metabolizes 2'3'-cGAMP and inactivates the STING pathway. 
In another study, it was shown that Mycobacterium tuberculosis evades host immune response through a bacterial phosphodiesterase (CdnP) which inactivates host 2'3'-cGAMP. Loss of ENPP1 attenuated Mycobacterium tuberculosis infection, as did the inhibition of CdnP, the phosphodiesterase of Mycobacterium tuberculosis [27] More recently, inactivation of porcine ENPP1 was shown to attenuate pseudorabies infection through an interferon- $\beta$ dependent response [28]. Many viruses generate antagonist proteins that can inactivate cGAS-STING pathway [29]. ENPP1 is differentially expressed in immune cells with low levels in NK cells, DC and macrophages and high levels in neutrophils [30]. ENPP1 is also expressed in a small subset of B-cells and studies suggest that these cells may be involved in modulation of T-cell activity [31]. Interestingly, ENPP1 expression was reported to be elevated in the M2 subtype of macrophages that are known to play a role in tumor promotion [28,32,33]. Other studies have indicated that expression of ENPP1 is increased in astrocytic tumors, breast cancers, and head and neck cancers [34-36]. Thus, inhibition of ENPP1 in humans may provide opportunities for treatment of cancers and pathogenic infections.

\section{Challenges in Development of Inhibitors of ENPP1 for Human Use}

Given the various functions for ENPP1 in regulating host immune responses, there is interest in development of ENPP1 inhibitors for human use. These inhibitors may have promising activity in human cancers and infectious pathologies. There are various practical challenges in development of these inhibitors. ENPP1 is a type II transmembrane glycoprotein that belongs to a family of ectonucleotide pyrophosphatase/phosphodiesterase (Enpp) family and consist of seven distinct proteins with distinct functions [37]. Thus, any inhibitor strategy will have to consider development challenges for specificity. In the published crystal structure of mouse ENPP1, there are important structural differences between ENPP2 and ENPP1. The N-terminal somatomedin-like (SMB) domains of ENPP1 do not interact with catalytic domains unlike those in ENPP2 [38,39]. ENPP1 appears to lack a hydrophobic pocket in contrast to ENPP2 although interdomain interactions are preserved [37-40]. Despite these challenges, our group and others have described novel selective and orally bioavailable inhibitors of ENPP1 [41-45].

Fundamental effects of ENPP1 inhibition on host immune response are still being determined. It is not known, for instance, if ENPP1 deficiency in mouse models impairs anti-tumor growth. Thus, optimal duration and intensity of ENPP1 inhibition is still being developed. This is important since systemic administration of these inhibitors can cause unwanted side effects due to excessive release of interferons. Interestingly, ENPP1 knockout mice are viable, thus pointing to possible avenues for development of such inhibitors. Prolonged administration of ENPP1 inhibitors may lead to unwanted effects on bony tissues and ectopic calcifications although this has been disputed in various studies in literature [46]. This is because bone and cartilage effects may not be entirely mediated by
ENPP1. In other studies, oral administration of pyrophosphate can attenuate the connective tissue calcifications mediated by ENPP1 mutations in mouse models [47].

\section{Conclusion}

As hyper-activation of STING pathway may lead to production of abnormally high levels of proinflammatory cytokines, it is necessary to develop therapeutics that target STING pathway indirectly. Inhibition of ENPP1 activity is one approach that may result in optimal activation of STING pathway, enough to have anti-tumor effects, and minimize unintended consequences. Given the role of ENPP1 in immune modulation and tumor promotion, there is an increased interest to develop novel therapies based on inhibition of the ENPP1 activity and this will emerge as an interesting area in the coming years.

\section{Acknowledgments}

We thank Dr. Hariprasad Vankayalapati for advice in developing this review.

\section{References}

1. Liu CH, Liu H, Ge B (2017) Innate immunity in tuberculosis: host defensevs pathogen evasion. Cell Mol Immunol 14(12): 963-975.

2. Nowarski R, Gagliani N, Huber S, Flavell RA (2013) Innate immune cells in inflammation and cancer. Cancer Immunol Res 1(2): 77-84.

3. Suzuki F, Pollard RB, UchimuraS, MunakataT, Maeda H(1990) Role of natural killer cells and macrophages in the nonspecific resistance to tumors in mice stimulated with SMANCS, a polymer-conjugated derivative of neocarzinostatin. Cancer Res 50(13): 3897-3904.

4. Jyonouchi H, Sun S, Itokazu N (2002) Innate immunity associated with inflammatory responses and cytokine production againstcommon dietary proteins in patients with autism spectrum disorder. Neuro psychobiology 46(2): 76-84.

5. Alfuwaires M, Altaher A, Kandeel M (2017) Molecular Dynamic Studies of Interferon and Innate Immunity Resistance in MERS CoV Non-Structural Protein 3. Biol Pharm Bull 40(3): 345-351.

6. Brown J, Wang H, Hajishengallis GN, Martin M (2011) TLR-signaling networks: an integration of adaptor molecules, kinases, and cross-talk. J Dent Res 90(4): 417-427.

7. Perez-Ramirez C, Canadas-Garre M, Alnatsha A, Molina MA, Robles AI, et al (2017) Interleukins as new prognostic genetic biomarkers in non-small celllungcancer.Surg Oncol26(3): 278-285.

8. Bock O, Yu H, Zitron S, Bayat A, Ferguson MW, et al. (2005) Studies of transforming growth factors beta 1-3 and their receptors I and II in fibroblast of keloids and hypertrophic scars. Acta Derm Venereol 85(3): 216-220.

9. Tomioka H, Shimizu T, Maw WW, Ogasawara K (2000) Roles of tumor necrosis factor-alpha (TNF-alpha), transforming growth factor-beta (TGFbeta), and IL-10 in the modulation of intercellular adhesion molecule-1 (ICAM-1) expression by macrophages during mycobacterial infection. Clin Exp Immunol 122(3): 335-342.

10. Burdette DL, Monroe KM, Sotelo Troha K, Iwig JS, Eckert B, et al. (2011) STING is a direct innate immune sensor of cyclic di-GMP. Nature 478(7370): 515-518.

11. Watson RO, Bell SL, Mac Duff DA, Kimmey JM, Diner, et al. (2015) The Cytosolic Sensor cGAS Detects Mycobacterium tuberculosis DNA to Induce Type I Interferons and Activate Autophagy. Cell Host Microbe 17(6): 811-819. 
12. Woodward JJ, Iavarone AT, Portnoy DA (2010) c-di-AMP secreted by intracellular Listeria monocytogenes activates a host type I interferon response. Science 328(5986): 1703-1705.

13. Fuertes MB, Kacha AK, Kline J, Woo SR, Kranz DM, et al. (2011) Host type I IFN signals are required for antitumor CD8+ T cell responses through CD8\{alpha\}+ dendritic cells. J Exp Med 208(10): 2005-2016.

14. Woo SR, Fuertes MB, Corrales L, Spranger S, Furdyna MJ, et al. (2014) STING-dependent cytosolic DNA sensing mediates innate immune recognition of immunogenic tumors. Immunity 41(5): 830-842.

15. Nielsen JS, Nelson BH (2012) Tumor-infiltrating B cells and T cells: Working together to promote patient survival. Oncoimmunology 1(9), 16231625.

16. Parkes EE, Walker SM, Taggart LE, McCabe N, Knight LA, et al. (2017) Activation of STING-Dependent Innate Immune Signaling By S-PhaseSpecific DNA Damage in Breast Cancer. J Natl Cancer Inst 109(1).

17. Konno H, Yamauchi S, Berglund A, Putney RM, Mule JJ (2018) Suppression of STING signaling through epigenetic silencing and missense mutation impedes DNA damage mediated cytokine production. Oncogene 37: 2037-2051.

18. Lau L, Gray EE, Brunette RL, Stetson DB (2015) DNA tumor virus oncogenes antagonize the cGAS-STING DNA-sensing pathway. Science 350(6260): 568-571.

19. Li K, Qu S, Chen X, Wu Q, Shi M (2017) Promising Targets for Cancer Immunotherapy: TLRs, RLRs, and STING-Mediated Innate Immune Pathways. Int J Mol Sci 18(12).

20. Moynihan KD, Irvine DJ (2017) Roles for Innate Immunity in Combination Immunotherapies. Cancer Res 77(19): 5215-5221.

21. Johnson K, Moffa A, Chen Y, Pritzker K, GodingJ, et al. (1999) Matrix vesicle plasma cell membrane glycoprotein-1 regulates mineralization by murine osteoblastic MC3T3 cells. J Bone Miner Res 14(6): 883-892.

22. Hosoda Y, Yoshimura Y, Higaki S (1981) A new breed of mouse showing multiple osteochondral lesions-twy mouse. Ryumachi 21 Suppl, 157164.

23. Hessle L, Johnson KA, Anderson HC, Narisawa S, Sali A, et al. (2002) Tissue-nonspecific alkaline phosphatase and plasma cell membrane glycoprotein-1 are central antagonistic regulators of bone mineralization. Proc Natl Acad Sci U S A 99(14): 9445-9449.

24. Bakdash G, Sittig SP, van Dijk T, Figdor CG, De Vries IJ (2013) The nature of activatory and tolerogenic dendritic cell-derived signal II. Front Immuno $14: 53$.

25. Li L, Yin Q Kuss P, Maliga Z, Millan JL, et al. (2014) Hydrolysis of 2'3'-cGAMP by ENPP1 and design of nonhydrolyzable analogs. Nature chemical biology 10:1043-1048.

26. Tao J, Zhou X, Jiang Z (2016) cGAS-cGAMP-STING: The three musketeers of cytosolic DNA sensing and signaling. IUBMB Life 68(11): 858-870.

27. Dey RJ, Dey B, Zheng Y, Cheung LS, Zhou J,etal.(2017) Inhibitionofinnate immune cytosolic surveillance by an $M$. tuberculosis phosphodiesterase. NatChemBiol13(2): 210-217.

28. Wang J, LuSF, Wan B,Ming SL, LiGL,et al. (2018) Maintenance of cyclic GMPAMP homeostasis by ENPP1 is involved in pseudorabies virus infection. Mol Immunol 95: 56-63.

29. Beach Board DC, Horner SM (2016) Innate immune evasion strategies of DNA and RNA viruses. Curr Opin Microbiol 32: 113-119.

30. Abbasi S, Shin DM, Beaty N, Masiuk M, Chen S, et al. (2011) Characterizationofmonoclonalantibodies to the plasma cell alloantigen ENPP1. Hybridoma (Larchmt) 30(1): 11-17.

31. Yoon J, Wang H, Kim YC, Yoshimoto M, Abbasi S, et al. (2016). Plasma cell alloantigen ENPP1 is expressed by a subset of human B cells with potential regulatory functions. Immunol Cell Biol 94(8): 719-728.
32. Kaneda MM, Messer KS, Ralainirina N, Li H, Leem CJ, et al. (2016) PI3Kgamma is a molecular switch that controls immune suppression. Nature 539(7629): 437-442.

33. Sautter CA, Auray G, Python S, Liniger M, Summerfield A (2018) Phenotypic and functional modulations of porcine macrophages by interferons and interleukin- 4. Dev Comp Immunol 84: 181-192.

34. Aerts I, Martin JJ, De Deyn PP, Van Ginniken C, Van Ostade, et al. (2011) The expression of ecto-nucleotide pyrophosphatase/ phosphodiesterase 1 (E-NPP1) is correlated with astrocytic tumor grade. Clin Neurol Neurosurg 113(3): 224-229.

35. Lau WM, Doucet M, Stael R, Huang D, Weber KL, Kominsky SL (2013) Enpp1: a potential facilitator of breast cancer bone metastasis. PLoS One 8(7): e66752.

36. Perez Valencia JA, Prosdocimi F, Cesari IM, Da Costa IR, Furtado C, et al. (2018) Angiogenesis and evading immune destruction are the main related transcriptomic characteristics to the invasive process of oral tongue cancer.

37. Kato K, Nishimasu H, Mihara E, Ishitani R, Takagi J (2012) Expression, purification, crystallization and preliminary X-ray crystallographic analysis of Enpp1. Acta Crystallogr Sect F Struct Biol Cryst Commun 68(7): 778-782.

38. Kawaguchi M, Okabe T, Okudaira S, Nishimasu H, Ishitani R, et al. (2013) Screening and X-ray crystal structure-based optimization ofautotaxin (ENPP2) inhibitors, usinga newly developed fluorescence probe. ACS Chem Biol 8: 1713-1721.

39. Nishimasu H, Okudaira S, Hama K, Mihara E, Dohmae N, et al. (2011) Crystalstructure of autotaxin and insight into GPCR activation by lipid mediators. Nat Struct Mol Biol 18: 205-212.

40. Jansen S, Perrakis A, Ulens C, Winkler C,Andries M, et al.(2012) Structure of NPP1, an ectonucleotide pyrophosphatase/phosphodiesterase involved in tissue calcification. Structure 20(11): 1948-1959.

41. Chang L, Lee SY, Leonczak P, Rozenski J, De Jonghe S, et al. (2014) Imidazopyridine- and purine-thioacetamide derivatives: potent inhibitors o f nucleotide pyrophosphatase/phosphodiesterase 1 (NPP1). J Med Chem 57(23): 10080-10100.

42. Lecka J, Ben-David G, Simhaev L, Eliahu S, Oscar J, et al. (2013) Nonhydrolyzable ATP analogues as selective inhibitors of human NPP1: a combined computational/experimental study. J Med Chem 56(21): 8308-8320.

43. Nadel Y, Lecka J, Gilad Y, Ben-David G,Forster D, et al. (2014) Highly potent and selective ectonucleotide pyrophosphatase/phosphodiesterase I inhibitors based on an adenosine 5'-(alpha or gamma)-thio(alpha,beta- or beta, gamma)- methylene triphosphate scaffold. J Med Chem 57(11): 4677-4691.

44. SharmaS,WestonA, Thode T,Gomez E,Kaadige M, et al. (2018) Discovery ofENPP1in heritors as agonistsofSTING pathway. In ProceedingsAACR. American Association of Cancer Research, Chicago, IL, USA, 1932.

45. Zelikman V, Pelletier J, Simhaev L, Sela A, Gendron FP, et al. (2018) Highly Selective and Potent Ectonucleotide Pyrophosphatase-1 (NPP1) Inhibitors Based on Uridine 5'-Palpha, alpha- Dithiophosphate Analogues. J Med Chem 61(9): 3939-3951.

46. Nam HK, Liu J, Li Y, Kragor A, Hatch NE (2011) Ectonucleotide pyrophosphatase/phosphodiesterase-1 (ENPP1) protein regulates osteoblast differentiation. The Journal of biological chemistry 286(45): 39059-39071.

47. Dedinszki D, Szeri F Kozak E, Pomozi V, Tokesi N, et al. (2017) Oral administration of pyrophosphateinhibitsconnectivetissuecalcification. EMBOMolMed9(11): 1463-1470. 


\section{Your next submission with Juniper Publishers} will reach you the below assets

- Quality Editorial service

- Swift Peer Review

- Reprints availability

- E-prints Service

- Manuscript Podcast for convenient understanding

- Global attainment for your research

- Manuscript accessibility in different formats ( Pdf, E-pub, Full Text, Audio)

- Unceasing customer service

Track the below URL for one-step submission https://juniperpublishers.com/online-submission.php 